\title{
The management of incontinence
}

\author{
JOHN C. BROCKLEHURST \\ M.D., M.R.C.P.(Ed.), M.R.C.P.(Glasgow) \\ Consultant Geriatrician, \\ Bromley and Sidcup Hospital Groups
}

INCONTINENCE of urine and faeces provides one of the great problems in geriatric medicine. It is a problem to which physicians on the whole have given little thought. Yet urinary incontinence in particular keeps large numbers of elderly people in hospital who could otherwise leave, and involves a disproportionate amount of nursing time. It is important, therefore, that physicians should have some knowledge of aging as it affects the bladder and the bowel, and that they should develop a rational approach to the problems of incontinence.

Incontinence of urine and incontinence of faeces have different causes, and must, therefore, be considered separately. Faecal incontinence is largely a preventable condition and will be dealt with briefly at the end of this paper. Urinary incontinence, on the other hand, is more frequent and more intractable. It is the main subject to be discussed.

Urinary incontinence will be considered under three headings-first, the characteristics of the aging bladder both in incontinent and nonincontinent people; second, investigation of incontinence ; and third, its treatment.

\section{The aging bladder}

There are three aspects of bladder function which are important to consider. These are bladder capacity, the quantity of residual urine and the presence or absence of uninhibited bladder contractions. In a normal younger person bladder capacity is $400-600 \mathrm{ml}$, residual urine is absent and uninhibited bladder contractions do not occur. In old people who are not incontinent, bladder capacity diminishes and the amount of residual urine increases. Thus the bladder neither fills properly nor empties properly. In addition, large uninhibited bladder contractions may occur during filling and may empty the bladder precipitately at its low capacity. In the aged incontinent bladder these parameters generally become more abnormal, but there is a degree of overlap. This is represented in Fig. 1. It would seem that while the normal younger bladder shows a normal capacity and the incontinent bladder tends to show the most abnormal capacity, there is a considerable variation in bladder capacity in old people whether

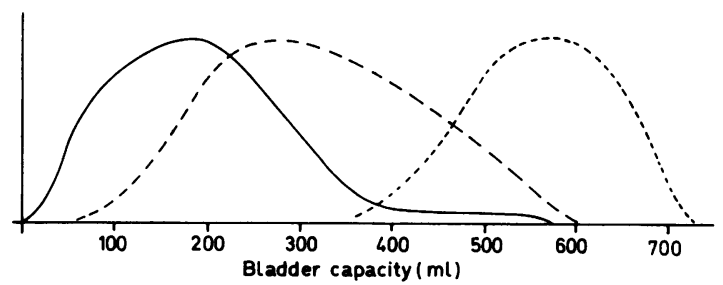

Fig. 1. Diagrammatic illustration of the range of bladder capacity in normal adults (- - - ), normal old people (- - - ) and incontinent old people (- $\longrightarrow$ ).

incontinent or not. The same variation applies to the volume of residual urine and also to the occurrence of uninhibited bladder contractions (Brocklehurst \& Dillane, 1966a, b).

Apart from this evidence of disordered bladder function in old age, it is also well known that old people suffer from precipitancy and nocturia. These clinical manifestations may reflect the functional changes noted above. A survey of the entire population of a general practice has recently shown the presence of nocturia in $64 \%$ of old people. It was present in both men and women, although commoner in men. There is also an increase in urinary infection in both sexes in old age, so that $20 \%$ of women over the age of 60 years and men over the age of 70 years are infected (Brocklehurst et al., 1967). In females descent and funnelling of the bladder outlet is common. Stress incontinence is present in $12 \%$ of normal old women. 


\section{The incontinent aged bladder}

As noted above, the incontinent bladcier shows changes similar to but more severe than the nonincontinent bladder in old age (diminished capacity, increased residual urine and the presence of uninhibited contractions). Examination by micturating cystogram shows the characteristics of the uninhibited neurogenic bladder in about twothirds of cases (Brocklehurst \& Dillane, 1967a). These are the presence of trabeculation, cellules and diverticula (Fig. 2). Micturating cystograms in
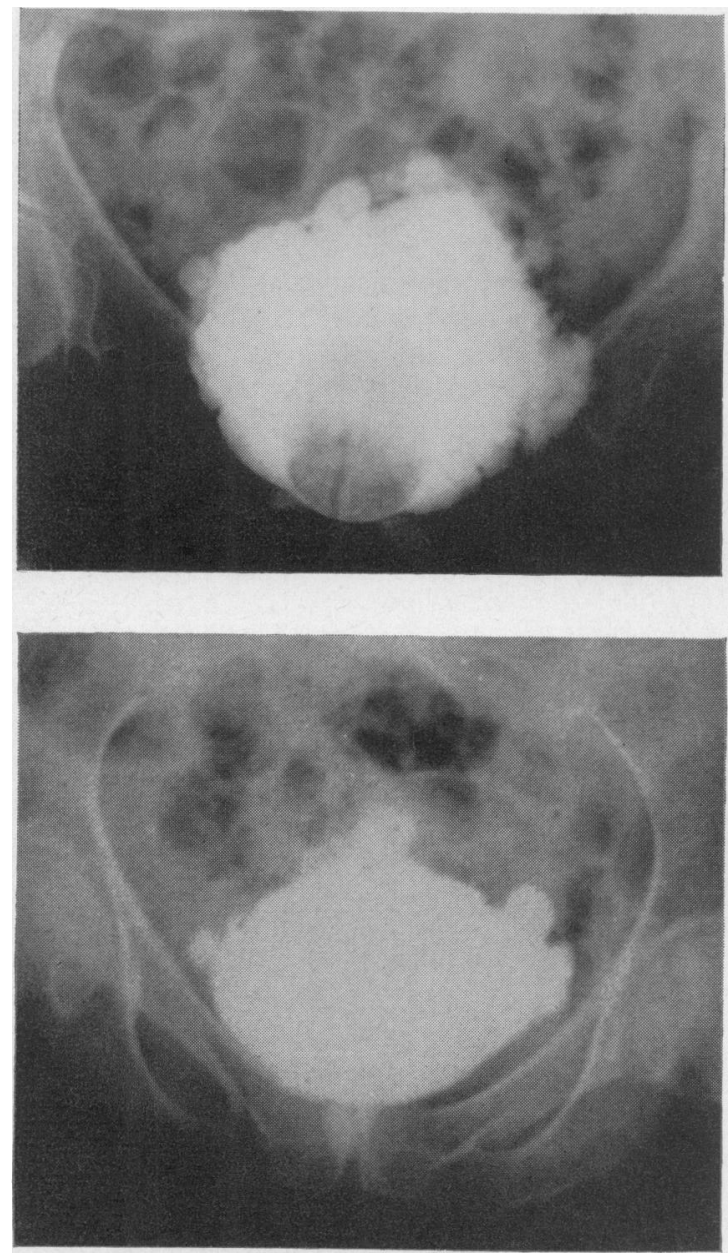

Fig. 2. Cystograms showing diverticula and cellule formation in a neurogenic bladder of old age.

incontinent aged women also show evidence of pelvic floor incompetence and funnelling of the bladder outlet in about half the cases (Fig. 3). These changes, together with those of the neurogenic bladder may co-exist.

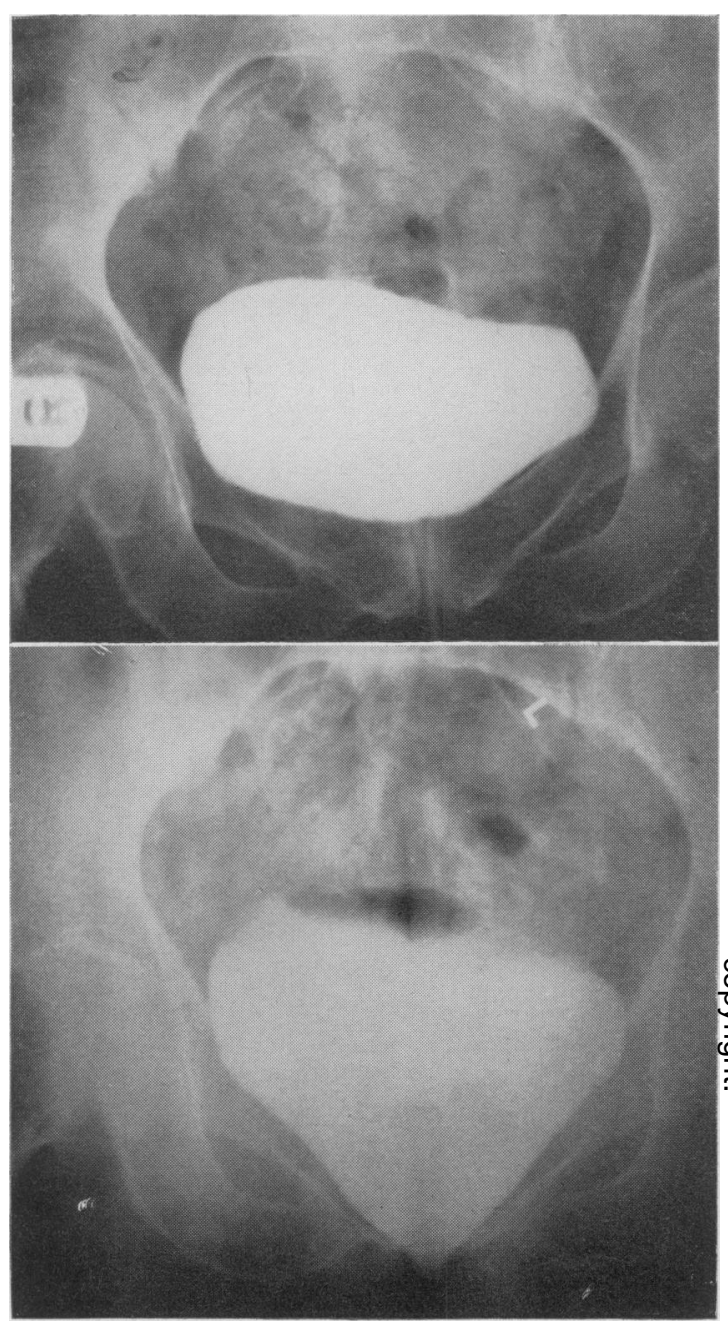

Fig. 3. Cystograms showing descent of the bladder base on standing together with funnelling of the bladder outlet. (The same patient recumbent and erect.)

The clinical diagnosis in a series of 100 incontinent elderly women in hospital was as follows:

Right hemiplegia

Left hemiplegia

Multiple strokes

Cerebral arteriosclerosis

Mental confusion

Parkinsonism

Other CNS diseases

Other non-neurological diseases

Thus over $80 \%$ of incontinent old women have disease of the central nervous system (Brocklehurst \& Dillane, 1966b). This is a finding which 
has been confirmed by other workers (e.g. Isaacs \& Walkey, 1964).

While most cases of urinary incontinence in old age are due to the uninhibited neurogenic bladder, nevertheless there are other causes and these must always be considerd. They are as follows:

Acute urinary infection,

Prostatic enlargement,

Uterine prolapse,

Conditions causing acute confusional states,

Retention of urine with overlow incontinence due to prostatic enlargement, faecal impaction or CNS lesions such as tabes dorsalis, Carcinoma of the bladder or prostate.

\section{The investigation of urinary incontinence}

It is important to differentiate between transient and established incontinence. Many old people come into hospital with diseases which cause acute confusional states (e.g. pneumonia, myocardial infarction, diabetes). Others are disorientated for the first $24 \mathrm{hr}$ because they are unable to adapt quickly to sudden environmental change. For these and other reasons many old people have a phase of urinary incontinence for the first few days in hospital. In these cases the incontinence is transient and will clear up as the underlying pathological state improves. Similarly many patients with acute cerebro-vascular lesions are incontinent of urine for the first few days in hospital and the incontinence then clears up.

The incontinence which we must consider here is established incontinence, present even when the patient becomes well orientated and sensible, and is undergoing rehabilitation. In such a situation investigation may include the undernoted procedures.

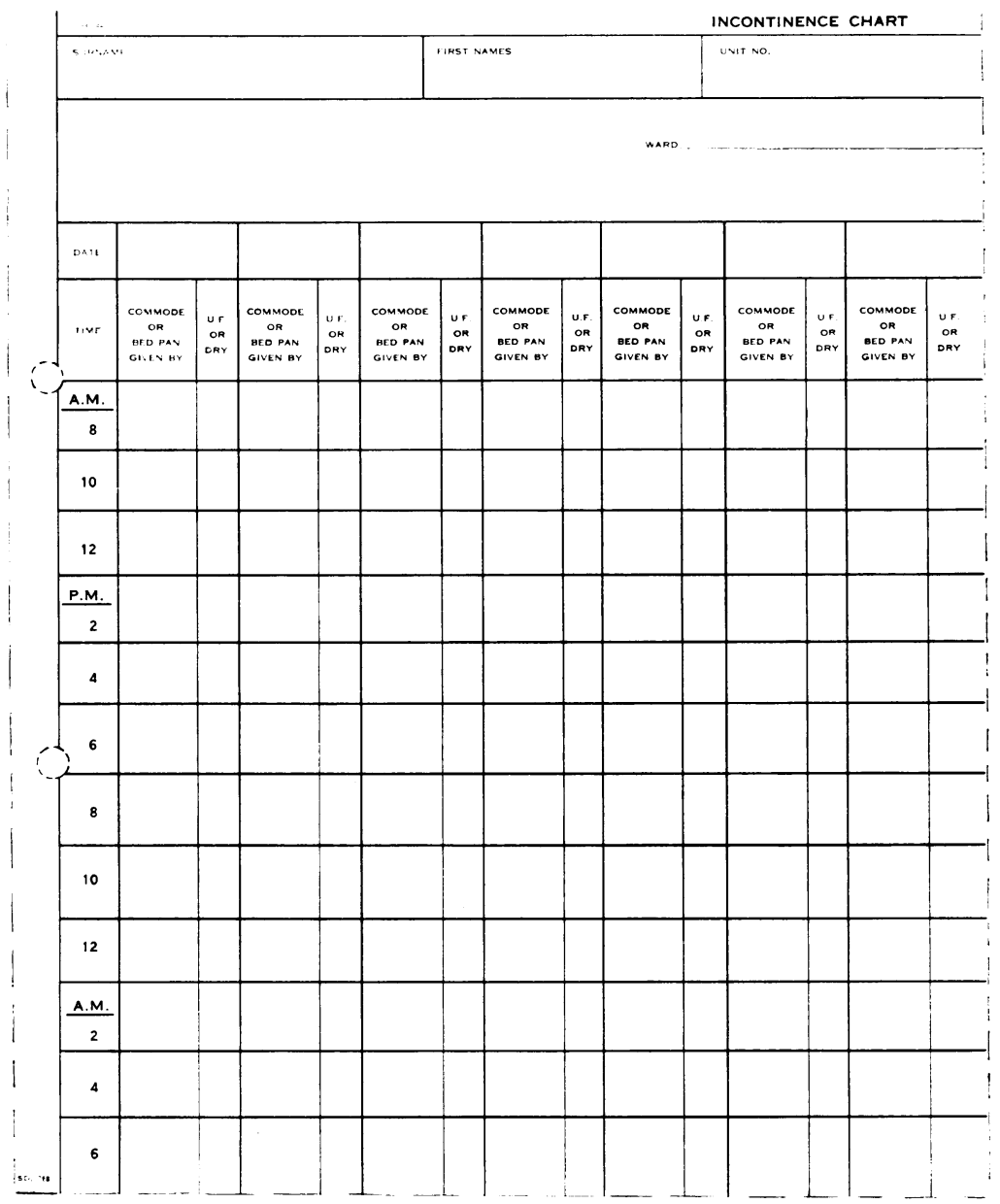

FIG. 4. Incontinence chart (half actual size). 


\section{Examination}

Urinary infection, faecal impaction or retention due to prostatic enlargement should already have been dealt with. If the vulva and vagina have not already been examined this should now be done.

\section{Charting}

To treat incontinence intelligently a record of its incidence throughout the $24 \mathrm{hr}$ should be made on an incontinence chart (Fig. 4). No physician would attempt to treat diabetes without charting the incidence of glycosuria during the $24 \mathrm{hr}$ : just as much care must be taken in charting the incidence of incontinence if it is to be properly managed. Incontinence charts require conscientious and intelligent nursing, and before their introduction into a ward the whole procedure of charting must be discussed in detail with the nursing staff.

Every $4 \mathrm{hr}$ the patient is examined by the nurse, who notes on the chart whether the patient is dry, incontinent of urine or incontinent of faeces. At the same time she takes the patient to the lavatory or gets her to use a commode or bedpan. If several patients are on incontinence charts in one ward, then it should be the specific task of one nurse to complete these charts every $4 \mathrm{hr}$. It is helpful in reading the completed chart if the occasions when the patient has been wet are ringed in red.

Incontinence charts serve two purposes. One is therapeutic inasmuch as they ensure that the patient's bladder is emptied every $4 \mathrm{hr}$. This of itself may cure the incontinence. The other is diagnostic. In a number of cases the chart will show that incontinence is a problem only at a certain time of the day or night, and may be simply managed by getting the patient up an hour earlier in the morning, or by missing out an early morning cup of tea.

\section{The cystometrogram}

Cystometrograms are made by running fluid into the bladder from a reservoir, either in increments or gradually at a certain number of millilitres per minute. The reaction of the bladder to increasing distention can then be noted. The cystometrogram will show the bladder capacity, the amount of residual urine, the time of the first onset of desire to micturate, the presence or absence of uninhibited bladder contractions and the cause of leakage if this occurs (an example of this is shown in Fig. 5). Cystometrograms are used to diagnose the various types of neurogenic bladder. In incontinence in old age they are not of great use (apart from research purposes), since it will be only the most exceptional patient who will not show some evidence of an uninhibited neuro-

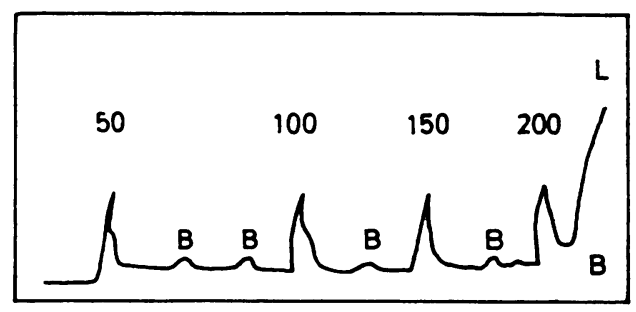

FIG. 5. Cystometrogram in an incontinent aged patient. Fluid added in increments of $50 \mathrm{ml}$, capacity $200 \mathrm{ml}$. Uninhibited bladder contractions which occur throughout filling, after addition of the iast increment cause leakage.

genic bladder. In this latter case other causes such as carcinoma may need consideration.

\section{Micturating cystograms}

Micturating cystograms are often difficult to carry out in incontinent old people because cooperation is limited. The micturating cystogram will show evidence of a neurogenic bladder, the presence of trabeculation, cellules and diverticula, but as noted above this is so commonly present that these findings although interesting are not of great value in management. Micturating cysto grams will also show those patients with marked descent of the bladder base and funnelling of thes outlet in whom a pessary or a repair operation may be indicated.

\section{Cystoscopy}

In elderly females diagnostic cystoscopy is not a difficult procedure. It would be an advantage to geriatricians if they were as familiar with the appearances inside the bladder as they are with those in the rectum. It is, of course, a more difficult procedure in incontinent women both because of diminished co-operation and also because the small bladder capacity may prevent adequate filling and thus interfere with the examination.

\section{General procedure}

The last three investigations are usually unnecessary. Once it is clear that incontinence is established, the patient should be put on to an incontinence chart. After a week a therapeutic trial with drugs should be made. It is, of course, understood that any urinary infection present should be diagnosed and treated during the patient's first few days in hospital. If drugs are unsuccessful, it is then worth while having a micturating cystogram and a cystoscopy done. The former will indicate bladder outlets needing attention, and the latter will exclude local lesions such as carcinoma and calculi. 


\section{Treatment of urinary incontinence}

There have been three main approaches to drug treatment of incontinence. These are: first, an attempt to control diuresis; second, the use of sex hormones for possible effect on the bladder; and third, pharmacological blockade of the sacral bladder reflex arc.

\section{The control of diuresis}

The simplest method of controlling diuresis is to limit the fluid intake at night. Attempts to improve on this have involved the use of the posterior pituitary hormone either as pitressin tannate in oil or pituitary snuff. These have had disappointing results (Dequeker, 1965).

\section{Sex hormones}

It is known that during pregnancy the capacity of the bladder increases, and this increase lasts for some months after parturition (Muellner, 1939). Experiments on rabbits have indicated that progestin is the hormone probably responsible (see Langworthy, Kob \& Lewis, 1940). On the basis of these findings a number of trials using sex hormones have been carried out but the preparations used have been oestrogens. In aged women, of course, oestrogens will provoke very striking changes in the vaginal epithelium. Some workers who have treated senile vaginitis with oestrogens have thought there was incidental improvement in bladder function (Geist \& Salmon, 1943 ; Wilson, 1948). However, there is as yet no good evidence to show that oestrogens are helpful in the treatment of incontinence.

\section{Pharmacological blockade}

The basic cause underlying the incontinence of old age is release of the sacral reflex bladder mechanism from inhibiting influences arising within the brain, with resulting overexcitability of this basic reflex. It therefore seems logical to attempt to diminish the incidence of uninhibited contractions and to increase bladder capacity by blocking transmission of nervous impulses somewhere within the sacral reflex arc. This may be attempted at three sites-at the parasympathetic nerve endings, the autonomic ganglia or within the spinal cord. Drugs having these effects have been fairly widely reported in the treatment of incontinence in old age, incontinence due to a neurogenic bladder in younger patients and in childhood enuresis. Good results have been reported with atrovine and other solanaceous alkaloids, with methantheline and propantheline and with the polysynaptic inhibitor hydramitrazine (Lissidon). Benefit from the use of ephedrine has also been reported and one of the side-effects of ephedrine is retention of urine. It is not clear why this should be since the sympathetic nerves are not regarded as playing a significant part in bladder control (Lapides, 1961).

Comparative review of the use of these drugs both singly and in combination has recently been completed (Brocklehurst \& Dillane, 1967b) and has indicated that in individual patients they may be helpful. Drug combinations suggested as particularly worthy of trial are: (a) propantheline and orphenadrine ; and (b) propantheline and atropine.

The correct use of such drugs in treating incontinence requires a regime based on the incontinence chart. They should be prescribed to anticipate times when the patient has been found to be wet. Usually they should be given at 22.00 hours and very often at some other time during the night. If at the end of a week no improvement in the incontinence chart is to be seen then the dosage may need adjusting or the drug combination changed. There is no point in continuing indefinitely with drugs unless a definite improvement has been shown.

Toxic effects, particularly of atropine in elderly people, must be borne in mind.

\section{Other methods of treatment}

Other ways of controlling urinary incontinence have been tried from time to time. One is to try and improve the tone of the skeletal muscle of the pelvic diaphragm, since laxity of the pelvic diaphragm undoubtedly causes descent of the bladder base and funnelling of its outlet in a large number of elderly women. This approach may be of some help but it only likely to improve stress incontinence. It may be brought about by exercises for the pelvic floor similar to those used antenatally, or by the application of faradism. The latter is generally badly tolerated by old people.

The use of an electronic stimulator to keep the external urethral sphincter closed has been tried (see Lancet annotation, 1965). The electrodes of such a stimulator are implanted near the sphincter and the wires are led beneath the skin, the stimulator itself being implanted on the anterior rectus sheath. This method is likely to result in high pressures within the bladder since uninhibited contractions will continue to occur and the outlet remains closed. Although good results have been reported, the difficulties are so considerable that it is not likely to be generally used in the aged.

\section{Appliances}

Disposable incontinence pads are now available which are useful in preventing accidental wetting of clothing or bedclothes but are not of great help in established incontinence. Two appliances are 
worth trying in males who will co-operate. The simplest is to use Paul's tubing applied over the end of the penis, a length of 3 or $4 \mathrm{ft}$ draining to a bottle at the bedside during the night. This is particularly helpful in ill or paralysed patients who are fairly immobile in bed, and not likely to pull it off. It may also be worn by an ambulant patient, and if successful then it is likely that a portable urinal will also be successful in such a patient.

Many portable urinals are far from satisfactory. One of the best is the pubic-pressure urinal made by Down Brothers. This consists of a ring which is firmly applied against the pubes and through which passes the penis. Pressure on the pubes tends to extrude the penis through the ring. If properly applied, it will remain correctly in position. The rest of the urinal is then fitted to a flange in this ring (Fig. 6). It is difficult to fit the urinal over the

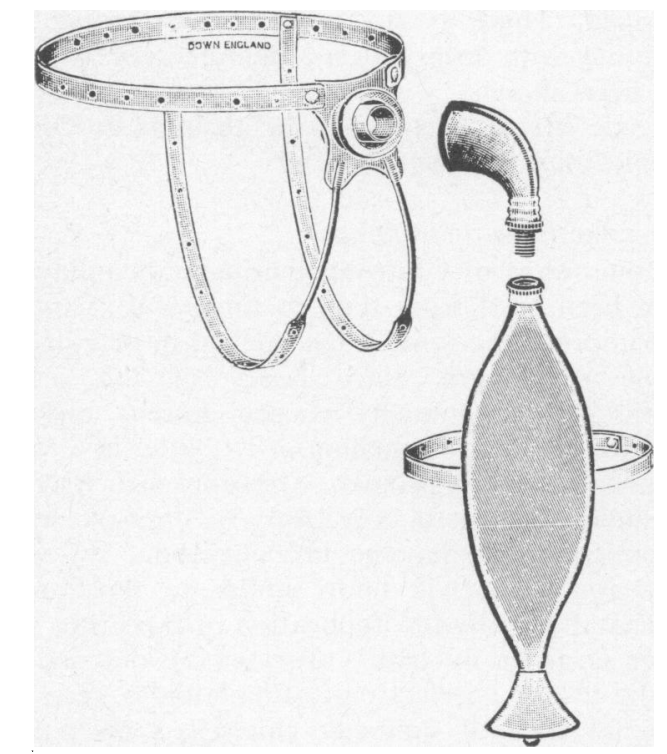

Fig. 6. Pubic Pressure Urinal manufactured by Down Brothers Ltd.

flange while the ring is being worn by the patient. Therefore, once the ring and its harness have been correctly fitted to the body they should be taken off and the whole urinal assembled. Urine drains into a bag which is worn on the leg. Provided due care is taken to see that the tubing does not become kinked, nor the bag overfilled, the collecting system works very satisfactorily. Many patients can use this urinal at night. It is sometimes a useful precaution to elevate the head of the bed on blocks to prevent backflow.

\section{Catheter drainage}

If none of the above methods of treatment is helpful then a decision has to be taken as to whether or not to use a permanent indwelling catheter to control the incontinence. With an indwelling catheter infection of the urine is inevitable and must be accepted. In the course of time, therefore, renal infection will follow. The decision that the physician has to make is whether the risks of infection outweigh the advantages of control of incontinence in an elderly patient whose life expectancy is almost certain to be limited to 1 or 2 years. Two situations in which catheterization is clearly indicated are-first, when urinary incontinence is keeping a patient in hospital who could otherwise lead a fuller and happier life in his own home or in an old person's home. Secondly, when a pressure sore is present and requires treatment.

Plastic Foley catheters are generally required for women, but Gibbon catheters may be satisfactory for men. In each case the catheter should be changed every 2 weeks or more often. After a new catheter has been put in it is worth while instilling $50-100 \mathrm{ml}$ of $1 / 3000$ chlorhexidine solution and clamping the catheter for $\frac{1}{2} \mathrm{hr}$. Leakage around the catheter sometimes occurs. If sediment is causing blockage it may be helpful to change the reaction of the urine by giving sodium acid phosphate by mouth. Sometimes the use of propantheline by mouth also seems to diminish leakage around the catheter.

Various views obtain on the use of systemic antibiotics in patients with indwelling catheters. Lorenze, Simon \& Linden (1959) recommend intermittent chemotherapy-using a full dose regime for 1 week each month. Crosby, Gibbon \& Damanski (1964) only give antibiotics during an acute exacerbation of infection. They recommend high fluid intake, avoidance of recumbency and efficient bladder drainage as the means of preventing ascending infection. Our procedure is to use antibiotics only to treat acute urinary infection which is causing systemic effects of symptoms.

\section{Faecal incontinence}

Faecal incontinence is almost entirely a preventable condition and should be regarded as such by physicians. They should insist that any incident of faecal incontinence is reported to them and is then investigated. Otherwise nurses may regard it as an inevitable, though unpleasant, accompaniment of old people in hospital.

Among the less common causes of faecal incontinence in old age are such underlying diseases as carcinoma and proctitis, or derangements such as rectal prolapse or disruption of the anal sphincter 
following surgery (e.g. for haemorrhoids). The two commonest causes are faecal impaction and neuromuscular inco-ordination.

Faecal impaction is probably the commonest cause of faecal incontinence in old age. It occurs particularly during the course of other illness, since confinement to bed or admission to hospital are both potent constipating factors in old age. As constipation continues, the faecal mass becomes desiccated and hard and provokes a secondary outpouring of mucus from the colon and rectum. This dissolves some of the faecal mass and presents as 'spurious' diarrhoea, generally uncontrolled.

Perhaps because elderly patients so often seem obsessional about chronic constipation, doctors tend to ignore it. Yet it can lead to unpleasant and serious complications-megacolon, volvulus and intestinal obstruction-as well as incontinence.

Disimpaction may be achieved by giving enemas. One or two enemas, however, are not usually enough. A daily enema should be given until a negative result is obtained and the physician (not the nurse) is certain that the whole colon has been emptied. This may take 5,6 or 7 days.

Measures to prevent recurrence must be taken once impaction has been relieved. If the patient's illness is passing and he is once more on his feet, there may be no further tendency for the condition to recur. Otherwise regular use of a combined laxative and wetting agent (such as Dorbanex, described recently by Raphael, 1966) should be recommended.

That there is an alternative cause of faecal incontinence in old age there can be no doubt. Whether or not neuromuscular inco-ordination is the underlying mechanism is not yet clear. Suggestive evidence is the fact that distending a balloon in the rectum of incontinent old men has been shown to provoke intrinsic contractions of the rectal musculature not seen in controls (Brocklehurst, 1951). This type of faecal incontinence requires further investigation.

Whatever its cause, this form of faecal incontinence can generally be well controlled by using a constipating mixture alternating with a laxative (Jarrett \& Exton Smith, 1960). Our practice is to give chalk and opium mixture daily for 5-6 days, and then produce a planned evacuation with an enema or suppository. The enema or suppository must be repeated as soon as it has had its effect. Great care must be taken to ensure that impaction is not produced.

\section{Conclusion}

Incontinence of urine or incontinence of faeces in old age are conditions requiring careful investigation, good nursing and appropriate medical treatment. If all these obtain then faecal incontinence is almost entirely preventable, and urinary incontinence almost always controllable.

\section{References}

Brocklehurst, J.C. (1951) Incontinence in Old People, pp. 68-87. Livingstone, Edinburgh.

Brocklehurst, J.C. \& Dillane, J.B. (1966a) Studies of the female bladder in old age. I. Cystometrograms in non-incontinent women. Geront. clin. (Basel), 8, 285.

Brocklehurst, J.C. \& Dillane, J.B. (1966b) Studies of the female bladder in old age. II. Cystometrograms in 100 incontinent women. Geront. clin. (Basel), 8, 306.

Brocklehurst, J.C. \& Dillane, J.B. (1967a) Studies of the female bladder in old age. III. Micturating cystograms in incontinent women. Geront. clin. (Basel), 9, 47.

Brocklehurst, J.C. \& Dillane, J.B. (1967b) Studies of the female bladder in old age. IV. Drug effects in urinary incontinence. Geront. clin. (Basel), 9 (In press).

Brocklehurst, J.C., Dillane, J.B., Griffiths, L. \& Fry, J. (1967) The prevalence and symptomatology of urinary infection in an aged population. (To be published).

Crosbie, R., Gibbon, N.O.K. \& Damanski, M. (1964) Bladder dysfunction in non-traumatic paraplegia. Lancet, i, 779.

DEQUEKER, J. (1965) Drug treatment of urinary incontinence in the elderly. Geront. clin. (Basel), 7, 311.

LANCET (1965) Electrical stimulaion of the bladder. A new prospect after spinal injury. Lancet, i, 851 .

GeIsT, S.K. \& SALMON, U.J. (1943) The relationship of oestrogens to dysuria and incontinence in post-menopausal women. J. Mount Sinai Hosp. 10, 208.

IsAACS, B. \& WALKEY, F.A. (1964) A survey of incontinence in elderly hospital patients. Geront. clin. (Basel), 6, 367.

JARRETT, A.S. \& EXTON SMITH, A.N. (1960) Treatment of faecal incontinence. Lancet, i, 925.

LANGWORTHY, O.R., KOLB, L.C. \& Lewis, L.G. (1940) Physiology of Micturition. Williams \& Wilkins, Baltimore.

LAPIDES, J. (1961) Physiology of the urinary sphincter and its relation to operations for incontinence. Brit. J. Urol. 33, 284.

LORENZE, E.J., SimON, H.B. \& Linden, J.L. (1959) Urologic problems in rehabilitation of hemiplegic patients. $J$. Amer. med. Ass. 169, 1042.

Muellner, S.R. (1939) Physiological bladder changes during pregnancy and the puerperium. J. Urol. 41, 691 .

RAPHAEL, J.H. (1966) Constipation in the elderly - a new treatment. Geront. clin. (Basel), 8, 160.

WILSON, T.S. (1948) Incontinence of urine in the aged. Lancet, ii, 374. 